\title{
ONLINE TUTORING THROUGH AN INTEGRATED PLATFORM TO SUPPORT LEARNING MATHEMATICS AT LOWER SECONDARY SCHOOL
}

\author{
Cecilia Fissore ${ }^{1, *}$ Marina Marchisio ${ }^{2, \dagger}$ and Sergio Rabellino ${ }^{3 *}$ \\ ${ }^{I}$ Department of Foreign Languages and Literatures and Modern Cultures, University of Turin, Via Giuseppe Verdi 10, \\ 10124, Turin, Italy \\ ${ }^{2}$ Department of Molecular Biotechnology and Health Sciences, University of Turin, Via Nizza 52, 10126, Turin, Italy \\ ${ }^{3}$ Computer Science Department, University of Turin, Corso Svizzera, 185, 10149, Turin, Italy
}

\begin{abstract}
The technologies and online supports that can offer students study opportunities have increased a lot in recent years, but often students do not use computers or mobile devices in school and, in general, for educational purposes. The Action of the University of Turin, within the "Ragazzi Connessi" project, proposes strategies for school recovery in Mathematics which involve the introduction of an online service built around an integrated Moodle platform with an advanced computing environment, an automatic assessment system and a web conference service, which enable the use of innovative didactics methodologies. The project involved teachers and students from three different secondary schools in the city of Genoa. This paper shows the main aspects of the platform and the strategies for school recovery developed inside the Action, in particular mathematics recovery path for students, carried out entirely online.
\end{abstract}

\section{KEYWORDS}

Advanced Computing Environment, Innovative Teaching Methodologies, Integrated Moodle Platform, Mathematics, Online Tutoring, School Recovery

\section{INTRODUCTION}

In recent years, the use of e-learning platforms where students can always have access to school materials and have study support, has developed exponentially (Giuliani et al., 2015; Valle et al., 2010). Today's students are often referred to as digital natives and live in a world surrounded by technology (Prensky, 2001). However, the actual use of the technologies by students is still rather superficial and is mostly limited to play games, messaging or web browsing (Fini, 2011). Indeed, it is important that students can use technologies and mobile devices also in school or, more generally, for educational purposes, and it is important that students are instructed to use them correctly. Digital competence has been included by the European Union among the eight key skills for lifelong learning outlined by the Recommendation of the European Parliament and of the Council in 2018 (2018/C 189/01), confirming that educational institutions must have a significant role in this sector. It is therefore needful to train teachers on the use of digital resources through innovative and interactive teaching methodologies, in order to innovate their teaching practices. The project "Ragazzi Connessi - Online to develop talents and offer orientation opportunities" proposes the application of innovative learning techniques in the schools of Genoa, through integrated interventions. The main objectives of the project are to fight educational poverty and school failure improving cohesion between the school and social communities. Within the project, started in September 2018, several partners collaborate to propose different and complementary actions:

- $\quad$ coaching and peer education interventions for the enhancement of disciplinary and transversal skills;

- dialogue facilitation activities through narration and reflection methodology;

- virtual learning paths and online tutoring in the logical-mathematical field. 
The Action of the University of Turin "Virtual Learning Paths" exploits the skills gained by the School of Tasks project in the City of Turin (Barana et al., 2017; Cavagnero et al., 2015; Giraudo et. Al., 2014) proposing the teaching and learning of Mathematics through new technologies and innovative methodologies with the aim of counteracting school failure in Mathematics. All activities take place online through a Moodle platform, browsable with any mobile device, integrated with a web conference service, an Automatic Assessment System (AAS) and an Advanced Calculation Environment (ACE). An ACE is a software system which allows numerical and symbolic calculation, geometric visualization in two and three dimensions and the develop of interactive components that allows you to view how a result varies as the input data changes; this is a very powerful and flexible tool for learning math. This article presents the platform and strategies of the Action for contrasting school failure. The Action so far has involved 20 teachers and 50 students from 4 lower secondary schools of Genoa. In particular, the math recovery course for students will be presented, which took place entirely online.

\section{ONLINE TEACHING STRATEGIES FOR THE RECOVERY OF SCHOOL FAILURE}

Mathematics is undoubtedly one of the school disciplines in which students generally have the greatest difficulties, which in some cases may even compromise the relationship with this discipline. Often the student who finishes the lower secondary school already has a history of failures in this subject that lead him to face it with fear or disinterest. To recover the difficulties in Mathematics, teachers and schools, but also students and parents, devote a lot of resources in terms of time and actions taken. The University of Turin has designed, studied and developed innovative methodologies for the reduction of school failures, such as:

- the use of a Virtual Learning Environment for collaborative learning and online tutoring (Barana \& Marchisio, 2016; Brancaccio et al., 2019; Fissore et al., 2019);

- the use of an ACE for interactive materials and for problem solving (Brancaccio et al., 2015);

- the use of an AAS for the construction of online tests with interactive feedback for recovery and enhancement (Barana et al., 2018a; Barana et al., 2018b).

The use of these new methodologies allows to propose a recovery intervention different from the traditional one with the use of new technologies (Turrentine and Macdonald, 2006; Ferrari, 2011). It also allows the development of digital skills in students, the enhancement of interest in the subject and confidence in the chance of success, as well as allowing the development of knowledge and skills related to learning Mathematics. The protagonists of the strategies and actions to be implemented are students with disciplinary deficiencies who need recovery. At the same time, however, their teachers are also involved: they are the first to intervene in student's recovery and they could use these methodologies for teaching with the whole class too. The strategies of the Action for the recovery of school failure are splitted in two main and complementary themes:

- the recovery path for students with the use of new methodologies;

- training of teachers on the use of new methodologies.

The training course for teachers, after a first 5-hour face-to-face training in presence, took place entirely online, while the recovery path took place entirely online. This was made possible by the integration of the platform with a web conference system, enabling remote interactions (audio, video, chat and PC screen sharing). The Action's Moodle platform, which can be visited at the link https://ragazziconnessi.i-learn.unito.it, was set up by the ICT Service of the Computer Science Department of the University of Turin. The integration of the platform with an ACE allows the distribution of interactive material and tests with various types of questions (not only multiple-choice questions but also open answers, questions with graphs and formulas, all of them particularly suitable for learning Mathematics) with automatic assessment and immediate feedback. The development of this platform allowed the design and implementation of educational activities based on the three methodologies mentioned above. The training course for teachers illustrated the innovative teaching methods for recovery and their possible use with students, to carry out online or face-to-face activities in blended modality using the platform. In the teacher training course, synchronous (five online one-hour meetings) and asynchronous training activities were provided (forums, questionnaires, database of available materials to consult and to use). A platform course has been created for each teacher in order to directly experience the methodologies proposed with their own classes. The teachers were also involved in organizing the student recovery path, which took place in parallel with their training course, to identify their students who 
needed a recovery in Mathematics. Students who had an insufficiency between 4 and a half and 5 and a half were chosen; students with very serious deficiencies have been referred to other interventions because they often require specific attention. The recovery path for these students, which in this first phase of the project was tested in a pilot version, took place entirely online. The duration of the recovery path was five weeks from the beginning of May, one and a half months before the summer break. Students were followed for one month by specially trained university tutors on the disciplinary topics reported by the teachers. The tutors were chosen specifically in the university environment to have greater effectiveness in the tutoring action since, for personal and school career issues, they are much closer to the students. All teachers had access to their students' recovery path and were able to check the activities they carried out, view all the materials made available by the tutor, if they wanted to use them with the whole class.

\section{ONLINE TUTORING FOR THE RECOVERY PATH}

The recovery path for students on the platform involved a total of: 7 teachers; $536^{\text {th }}$-grade or $7^{\text {th }}$-grade students from 12 sections of 4 lower secondary schools in the city of Genoa; 3 university tutors; 1 responsible for training and supporting tutors, organizing the path on the platform and keeping in contact with the teachers. Students were divided into 8 groups with the following criteria: no more than $5 / 6$ students per group and possibly from the same teacher. In this way, the organization and supervision by the teacher himself was made easier and the participation of the students was stimulated by the presence of their classmates. Eight platform courses were designed and set up, one for each group. The respective course could be accessed at any time with personal credentials: the students, the tutor (one for each course) and the student teacher. Each recovery path included:

- 5 one-hour weekly meetings online where students were able to interact with the tutor exposing their doubts, difficulties and unclear topics;

- the exploration of interactive files and the execution of tests with automatic assessment for review, created by the tutor on the topics covered during the tutoring or reported by students.

The online meetings took place in the afternoon after school, on a day of the week established with the teacher, and the students connected with their computer or mobile device. During online meetings the tutor could share his screen with students, showing interactive materials or using the ACE to make calculations and show the resolution of an exercise on a problem. The tutor and students could communicate via audio and chat; webcams option usually do not add information to the meeting and could be a distraction from the main objective which is to learn something, so usually we asked tutors not to enable them. Figure 1 shows an example of an online meeting seen from the point of view of a participating student. Along the entire project the teachers gave fundamental support for the organization of the recovery process: for the collection of the names of the students with deficiencies in Mathematics; for the presentation of the recovery path to students; for the communication of the access credentials to the platform; and for the explanation of how to navigate it. The research question for this Action was whether this recovery model could work with young students exclusively online. A first unknown factor was the students' reaction to dealing with a tutor they had never seen and known in person but exclusively through online meetings without even using the webcam. A second unknown at an organizational level was whether the students would be able to access the platform independently, to view the recovery path and to navigate correctly between the various contents and to connect to the online meeting. In this regard, the design of the recovery path was focused on making the navigability of the platform as intuitive and clear as possible. In addition to the support of the teachers, the students had a Helpdesk service on the platform always available, in which they could open a ticket to request assistance for their personal problems. This Helpdesk service was essential to quickly resolve student access problems, communicated in some cases also with the support of parents, and to ensure that they participated in the platform activities without becoming discouraged or losing interest. Finally, week by week, a close monitoring of students' access to the platform and a report to the respective teachers was carried out in order to give any assistance to students who had not been able to access. 


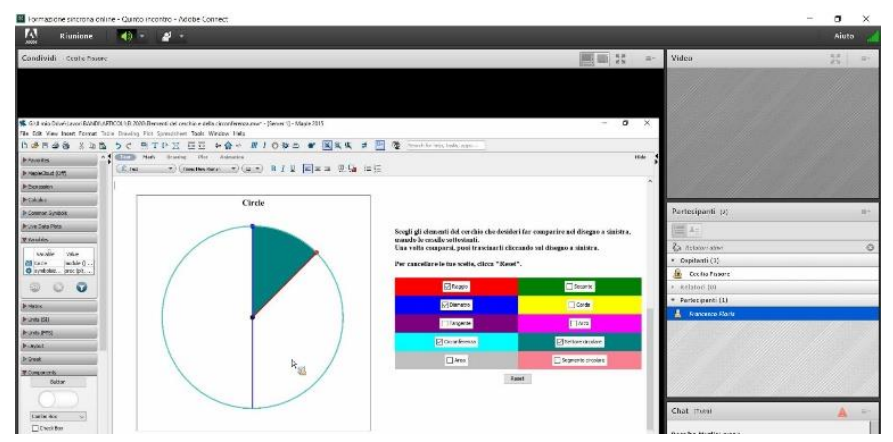

Figure 1. Example of online meeting from a student's perspective

At the beginning and end of the recovery process, students completed an initial and final questionnaire and the teachers filled out a final questionnaire on their students' recovery path. The structure and format of the platform course were the same for each course and are represented in the following figure (Figure 2).

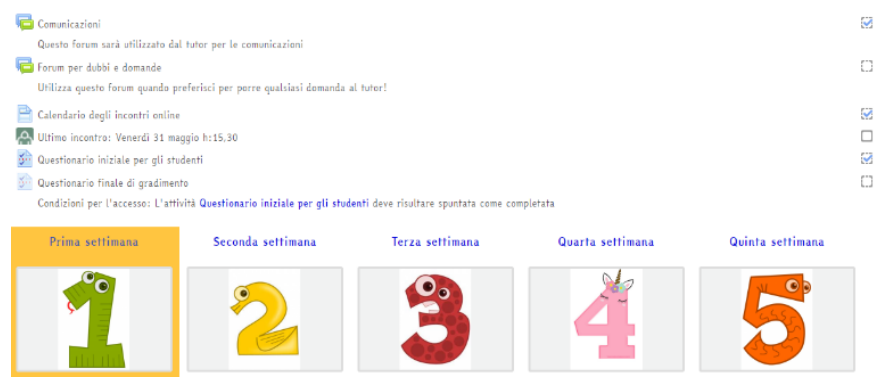

Figure 2. Example of a platform course for the recovery path

In each path has been included: a forum for communications by the tutor (to remember online appointments or to report the availability of the material); a Forum for students' questions; the calendar of online meetings; the virtual room for online meeting; an initial and final questionnaire. Both forums have been set up as mandatory subscriptions, in this way all course participants receive an email with every intervention added to the forum, both as a reminder for online meetings and as an incentive to use this resource. In some cases, the students did not have a personal email address and provided that of the parents, involving them directly within the project. The use of the platform makes it possible to track all student activities within the course. For each resource or activity in the course, it is also possible to set a criterion for completing the activity, so that you can automatically check the activities completed by the students and set access criteria to other sections, providing guidance through the online materials. The course had 5 sections, one for each week. Within each section, the tutor included interactive materials and tests with automatic assessment on the topics covered during online meetings, for further review and consolidation of knowledge. During the online meetings, tutors reviewed the disciplinary topics indicated by the teacher and asked students if they had doubts about specific aspects or requests to review other topics, after which they created and made available to the students some material, which they could explore and carry out during the week before the next meeting. Students could also use the forum at any time to ask questions to the tutor, about theoretical topics, about the online materials or about the use of the platform. Figure 3 shows an example of interactive material created with the ACE, to review the equivalent fractions with the use of pie charts. The integration of the platform with the ACE allows students to view a material directly embedded the platform's pages without the needs of installing the program while maintaining the interactivity on educational resource. In this case, students can enter the numerator and denominator of two fractions in the boxes, represent them graphically and check whether the two fractions are equivalent by receiving immediate feedback. The exploration can be repeated as many times as the students wish and, in this way, they can also learn a procedure for studying the mathematical concept. 


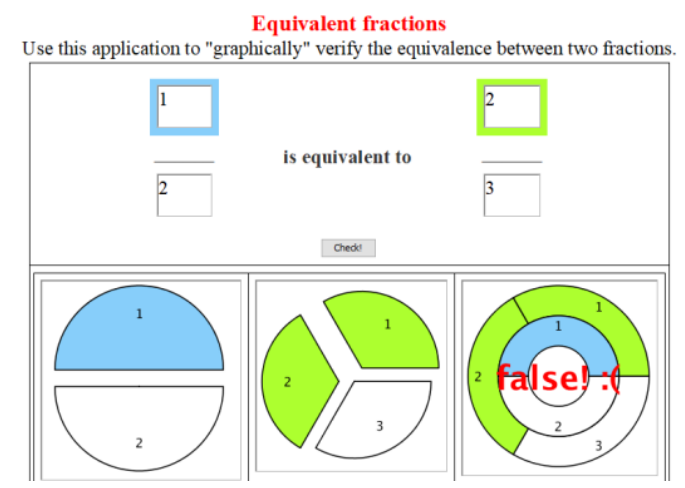

Figure 3. Example of interactive material created by tutors

The second type of material for recovery were tests with automatic assessment, very important for formative assessment (Barana et al., 2018a). Through them the students could carry out exercises with various types of questions having immediate and interactive feedback on the correctness of the answer and the possibility to try the question again, learning from his mistakes. Fig. 4 shows an example of question always inherent to equivalent fractions created with the AAS.

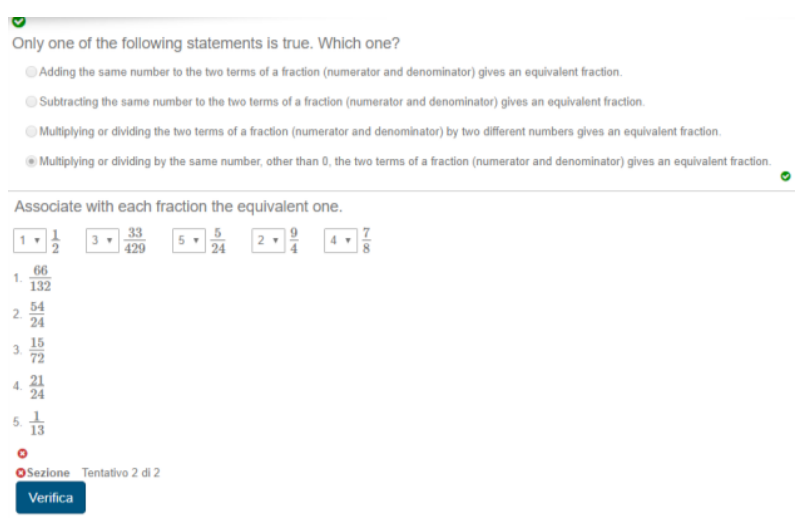

Figure 4. Example of question with automatic assessment and interactive and immediate feedback

In the first part of the question the student is asked to reflect on the theoretical definition of equivalent fractions choosing the correct answer among the four possible. In the second part, an application of the definition is proposed by associating the number of the equivalent fraction among those proposed to 5 fractions. The student in both sections of the question has the "Verifica" (which means "check" in italian language) button available to verify the correctness of the answer and it has 2 attempts to give the answer. In this way, if the student makes a mistake on the first attempt, he can rethink the reasoning and try to correct himself. The possibility to have multiple attempts available is very important for students' self-confidence.

\section{ANALYSIS OF THE RESULTS}

To understand the appreciation or otherwise of the students and their teachers on the recovery path and their considerations on the innovative methodologies proposed within it, we analyzed:

- the participation of students in online meetings;

- the activities carried out by the students on the platform;

- the collaboration through forums;

- $\quad$ students' answers to the initial and final questionnaires;

- teachers' answers to the satisfaction questionnaire on their students' progress. 
From the initial questionnaire, to which only 22 students answered in total, we were able to get a general overview of the students in different aspects of Mathematics and their expectations at the beginning of the course. In the first question the students had to give themselves a score from " $1=$ insufficient" to " $5=$ excellent" in different aspects included in the following table.

Table 1. Student responses to different aspects of Mathematics

\begin{tabular}{llc}
\hline & Mean & Dev. Standard \\
\hline Interest in the subject & 2,96 & 1,27 \\
\hline Knowledge of the subject & 2,60 & 0,91 \\
\hline Participation in the class lesson & 3,72 & 1,06 \\
\hline Study at home & 3,52 & 1,00 \\
\hline Confidence in the possibility of being able to recover & 3,08 & 1,41 \\
\hline
\end{tabular}

As can be seen from the mean and the standard deviation of the results, the initial situation was not very critical, and this is in line with the choice to direct the course to students with not too serious gaps. To the open question "Why are you having difficulties in this matter?" the students' most frequent answers were: "Because I am not passionate about the subject"; "Because I know things in theory, my difficulty is to put them into practice"; "I'm not good at math"; "Sometimes I'm not focused during the lesson"; "Because I have gaps"; "I don't really like it"; "I can't remember the formulas or all the rules by heart". These responses confirm what was said in the previous paragraph. Mathematics is seen as a difficult and uninteresting subject by students, very notional and mnemonic, in which it is only important to know how to do well the calculations. Finally, to the open question "What do you expect by participating in this project?" all students replied that they hope to improve and better understand the various topics; in two cases the " be more self-confident" was mentioned, in two others the "taking good marks" and only in one case "being able to have more interest". Out of 53 students, 30 students actively participated in the recovery path on the platform by participating in the online meetings, connecting to all or only some (frequencies shown in Figure 5).

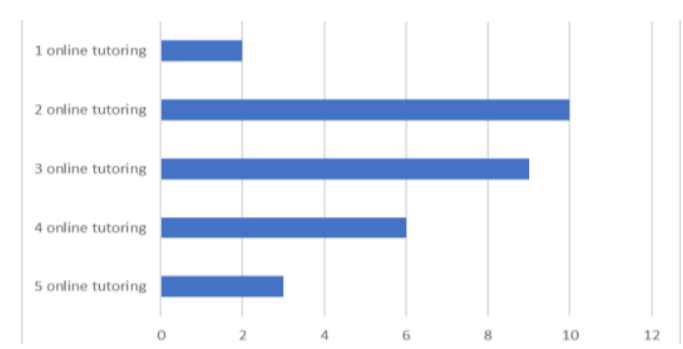

Figure 5. Frequency of students in online tutoring

The highest percentages concern participation in 2 or 3 online tutoring but the percentage on participation in 4 and 5 online tutoring is also good; the percentage of attendance to a single online tutoring is quite low. This data is encouraging because it means that after the first meeting the students were at least curious and interested enough to want to participate to the following ones. In some cases, the students did not participate to the online meetings but consulted the material and the activities on the platform, while 13 students never accessed the platform. Analyzing the completion of the activities in the assessment register, we found that 23 students completed at least one resource or one activity. Furthermore, there was no correlation between the number of people attending online meetings and the number of completed activities. There are, in fact, cases of students who participated in 3 online meetings or more and completed few or no activities; but there are also students who have completed many activities but attended few or no meetings. The only evidence in these results is that most of the students who did not attend any online meeting did not even complete the activities. This data shows that students need a guide to navigate the platform and discover its contents but also to interest and intrigue them and test themselves. The final questionnaire, which was answered by 15 students, revealed that $50 \%$ of the students mainly used the PC, $44 \%$ the smartphone and $6 \%$ the tablet to follow the recovery process. The data regarding the smartphone is a very positive result on the earlier talk about using mobile devices also for educational purposes. Table 2 shows a summary of the students' responses on the satisfaction of different aspects of the recovery process, including: the use of the platform, the web conference tool, the 
tutor's support, online collaboration and the proposed methodologies. The students had to answer by entering a value from " $1=$ not at all" to " 5 = very much". The results are positive. Especially the students appreciated the relationship with the university tutors and their explanations and the fact of being able to follow the path in online mode and use the platform. The students also enjoyed the interactive material and the computer exercises and tests with the automatic assessment made available on the platform. $80 \%$ of students have chosen the "very much" answer to the question "Would you like to have a platform and be able to use the computer even in normal school lessons?".

Table 2. Summary of the students' answers to the final questionnaire on various aspects of the online course

\begin{tabular}{lcc}
\hline & Mean & Dev.St. \\
\hline Were the university tutor's explanations interesting? & 4,5 & 0,64 \\
\hline Did you feel comfortable with the university tutor? & 4,8 & 0,56 \\
\hline How much did you appreciate being able to take the online course? & 4,7 & 0,49 \\
\hline Was it easy to use the platform? & 3,5 & 1,30 \\
\hline How much did you appreciate having the interactive material made available on the platform? & 4,4 & 0,91 \\
\hline $\begin{array}{l}\text { How much did you appreciate being able to perform exercises and checks on the computer with } \\
\text { automatic assessment? }\end{array}$ & 4,1 & 1,06 \\
\hline $\begin{array}{l}\text { How much did you appreciate being able to communicate with the tutor and classmates through } \\
\text { the platform? }\end{array}$ & 4,5 & 0,92 \\
\hline Do you think these platform resources have helped you improve? & 4,3 & 0,90 \\
\hline $\begin{array}{l}\text { Would you like to have a platform and be able to use the computer even in normal school } \\
\text { lessons? }\end{array}$ & 4,7 & 0,72 \\
\hline
\end{tabular}

To also evaluate the impact of the course on the aspects of Mathematics required in the initial questionnaire (Table 1) we asked students the same question as the final questionnaire. The results are very good because in all aspects the scores have improved (Table 3).

Table 3. Comparison of students' answers on various aspects of Mathematics between initial and final questionnaires

\begin{tabular}{lllll}
\hline & Mean before & Mean after & Dev.St. before & Dev.St. after \\
\hline Interest in the subject & 2,96 & 3,73 & 1,27 & 0,96 \\
\hline Knowledge of the subject & 2,60 & 3,47 & 0,91 & 0,64 \\
\hline Participation in the class lesson & 3,72 & 3,87 & 1,06 & 0,83 \\
\hline Study at home & 3,52 & 3,67 & 1,00 & 0,62 \\
\hline Confidence in the possibility of being able to recover & 3,08 & 3,53 & 1,41 & 1,46 \\
\hline
\end{tabular}

For $73 \%$ of students grades in Mathematics improved after the course and recovered from the difficulties they had in this subject. To the open question "What did you like most by attending this recovery path?" the most significant responses were: "Helping each other both with the tutor and with friends"; "The help of the tutor"; "The possibility of being able to communicate through the platform"; "The fact that the computer was used"; "Studying in this way"; "That I could do math with a person I have never seen, but above all recover that it was my main goal"; "All"; "Share the explanations given with my classmates"; "Being able to talk and communicate my math doubts directly from home and to be able to recover"; "When the tutor helped us with our homework." Finally, we asked students if they had suggestions for improving the recovery path and everyone asked to make it last longer. All the teachers involved were very present and played a very active role within the student recovery process. In fact, they viewed many, if not all, the activities made available on the platform by the tutor and supervised the work done by their students. Their responses to the satisfaction questionnaire on the recovery path indicate that they have found a lot of satisfaction from the students and believe that the path was useful.

\section{CONCLUSION}

The recovery path for students within the Action of the University of Turin for the "Ragazzi Connessi" Project involved 7 teachers and 53 students from four lower secondary schools in the city of Genoa. The analysis carried out shows that the exclusively online method with which the path was provided has had good success. 
The students had no difficulty in relating to a university tutor whom they did not see and know in person and greatly appreciated his help and explanations. Despite some initial difficulties, overcome with the help of teachers, parents and the Helpdesk service, students appreciated the use of the platform and would like it to be used during normal lessons. The students also appreciated the opportunity to participate in online meetings with the tutor and their classmates and appreciated the proposed methodologies (interactive files for recovery and tests with automatic assessment and interactive feedback). The course helped students to overcome difficulties in Mathematics and increase interest in the subject and in their self-confidence. The teachers' opinion on their students' recovery path is very positive. These results are encouraging in view of the second edition of the course currently underway, which will involve a greater number of students. The training course for teachers will also continue within the Action with the aim of using the innovative methodologies proposed in normal teaching with students. This online tutoring through an integrated online platform can support the normal teaching of teachers. It can also be essential in times of COVID-19 emergency, such as the one we are experiencing now, where face-to-face teaching activities are suspended.

\section{REFERENCES}

Barana, A., Conte, A., Fioravera, M., Marchisio, M., Rabellino, S., 2018a. A Model of Formative Automatic Assessment and Interactive Feedback for STEM. Proceedings of 2018 IEEE 42nd Annual Computer Software and Applications Conference (COMPSAC), IEEE. Tokyo, Japan, pp. 1016-1025. https://doi.org/10.1109/COMPSAC.2018.00178.

Barana, A., Fioravera, M., Marchisio, M., Rabellino, S., 2017. Adaptive Teaching Supported by ICTs to Reduce the School Failure in the Project "Scuola Dei Compiti.". Proceedings of 2017 IEEE 41st Annual Computer Software and Applications Conference (COMPSAC). IEEE, pp. 432-437.

Barana, A., Marchisio, M., 2016. Dall'esperienza di Digital Mate Training all'attività di Alternanza Scuola Lavoro. Mondo Digitale, 15, 64, pp. 63-82.

Barana, A., Marchisio, M., \& Sacchet, M., 2018b. Advantages of using automatic formative assessment for learning mathematics. Proceedings of International Conference on Technology Enhanced Assessment, TEA 2018. Amsterdam; Netherlands, pp. 180-198.

Brancaccio, A., Esposito, M., Marchisio, M., Sacchet, M., \& Pardini, C., 2019. Open professional development of math teachers through an online course. Proceedings of the International Conference on e-Learning 2019. Porto, Portugal, pp. 131-138.

Brancaccio, A., Marchisio, M., Meneghini, C., and Pardini, C., 2015. Matematica e Scienze più SMART per l'Insegnamento e l'Apprendimento. Mondo Digitale, 14, 58, pp. 1-8.

Cavagnero, S., Gallina M. A., and Marchisio, M., 2015. Scuola dei compiti. Didattica digitale per il recupero dell'insuccesso scolastico. Mondo Digitale, 14, 58, pp. 834-843.

Ferrari, P.L., 2011. Le potenzialità dell'e-learning in educazione matematica e il ruolo della ricerca. Tecnologie Didattiche, 19, 3, pp. 136-141.

Fini, A., 2011. Nativi digitali. Un aggiornamento sulla discussione in rete. Bricks, 1, pp.136-142.

Fissore, C., Floris, F., Marchisio, M., \& Rabellino, S., 2019. University tutoring actions using an integrated online platform. Proceeding of 16th International Conference on Cognition and Exploratory Learning in Digital Age, CELDA 2019, IADIS Press. Cagliari, Italy, pp. 69-76.

Giraudo, M. T., Marchisio, M., \& Pardini, C., 2014. Tutoring con le nuove tecnologie per ridurre l'insuccesso scolastico e favorire l'apprendimento della matematica nella scuola secondaria. Mondo Digitale. 13, 51, pp. 834-843.

Giuliani, A., Moretti, G., Morini, A., 2015. Servizi di tutorato didattico e Obblighi Formativi Aggiuntivi, un'indagine empirica esplorativa: il caso del Dipartimento di Scienze della Formazione dell'Università Roma Tre. Italian Journal of Educational Research, 15, pp. 63-78.

Prensky, M., 2001. Digital Natives. Digital Immigrants. On the Horizon, 9, 5, pp. 1-6.

Raccomandazione 2018/C 189/01 del Parlamento Europeo e del Consiglio, 22 maggio 2018. Competenze chiave per l'apprendimento permanente.

Turrentine, P. and Macdonald, L., 2006. Tutoring Online: Increasing Effectiveness with Best Practices. NADE Digest. 2 , 2, pp. 9-18.

Valle, V., Epifania, F., Folgieri, R., 2010. Un esperimento di didattica online per il recupero delle insufficienze scolastiche per studenti delle scuole superiori attraverso strumenti del web 2.0. Proceedings of Didamatica 2010. Roma, Italy, pp. 201-205. 